\title{
Analysis on associated factors of uncontrolled hypertension among elderly hypertensive patients in Southern China: a community-based, cross-sectional survey
}

\author{
Li Yang ${ }^{1}$, Xiaoling $X u^{1 *}$, Jing Yan ${ }^{1}$, Wei Yu ${ }^{1}$, Xinhua Tang ${ }^{1}$, Haibin $W^{2}$ and Christy L Parkin ${ }^{3}$
}

\begin{abstract}
Background: The prevalence of hypertension in China has risen dramatically in recent decades, but it is not well understood if hypertension is adequately controlled in the elderly population in Southern China. A provincial survey was performed in order to estimate the prevalence of hypertension control and the associated factors in the elderly population.
\end{abstract}

Methods: A cross-sectional survey was conducted in 6 community health service centers across 12 counties in Southern China from October 2010 to April 2011. Recruitment included a total of 10644 hypertensive subjects aged 60 or older. Basic lab tests and physical examinations were administrated on each subject. In addition, each subject completed a standardized questionnaire.

Results: The 10644 participants (mean age of 70.3 years) included 5527 women (51.9\%), 5117 men (48.1\%), 3148 overweight subjects (29.57\%), 846 (7.95\%) obese subjects, 1654 smokers $(15.54 \%)$ and 1750 consumers of alcohol (16.44\%). The control, treatment and awareness of hypertension were $44.6 \%, 50.3 \%$ and $46.3 \%$, respectively. Most treated hypertensives (68.57\%) used combination therapy of antihypertensive medications, and those using long-acting antihypertensive medications had a higher rate of adequately controlled hypertension. Results showed that elderly, living in rural and suburban areas, low education level, family history of hypertension, smoking, excessive salt consumption, lack of physical activity, overweight, obese and diabetes were associated with uncontrolled hypertension.

Conclusions: Lack of adequate hypertension control is relatively high among the elderly in Southern China. Hypertension awareness and early treatment are needed in this population, especially among suburban population, as well as adopting appropriate antihypertensive medication therapy and healthy lifestyles.

Keywords: Control, Elderly hypertensives, Cross-sectional, Associated factors

\section{Background}

Cardiovascular disease (CVD) is one of the leading causes of death worldwide, and it is enormous burden in developed and developing countries [1]. As one of the most important risk factors of CVD, hypertension accounts for approximately $50 \%$ of coronary heart disease and $67 \%$ for the cerebrovascular disease burden worldwide [2]. Recently, a survey demonstrated a decreasing

\footnotetext{
* Correspondence: phoebe84331@hotmail.com

'Zhejiang provincial center for cardio-cerebrovascular diseases control and prevention, Zhejiang hospital, 12 Lingyin Road, Hangzhou, Zhejiang 310013, China Full list of author information is available at the end of the article
}

trend of hypertension in western countries, but an increasing trend among Southeast Asia and Oceania [3]. In China, hypertension has ranked first as a risk factor of CVD, and many associated complications, such as stroke, heart and renal diseases, which are major causes of mortality [4]. According to the 2002 National Nutrition and Health Survey (NNHS), the prevalence of hypertension in adult Chinese population of 60 years or older was $49.1 \%$, and the rates of awareness, treatment and control were $37.6 \%, 32.2 \%$, and $7.6 \%$, respectively [5].

Zhejiang province is located in Southern China, it has an aging population (60 years or older) of approximately 
7.5 million in 2011 which accounts for $13.39 \%$ of the total population. As one of the most rapidly developing provinces, dramatic social and economic changes, including rapid urbanization has occurred in Zhejiang over the past 2 decades. These factors, in part, contributed to the inadequate control of hypertension [6]. However, little is known about whether hypertension is adequately controlled among the elderly in Southern China. A survey was conducted with 10644 elderly hypertensive patients living in Zhejiang province to study awareness, treatment and control of hypertension, and investigate the associated factors of uncontrolled hypertension.

\section{Methods}

\section{Sampling}

This study conducted in Zhejiang province was a crosssectional survey administrated in 6 community health centers across 12 counties. A multistage stratified random cluster sampling was used to include the subjects. In the first stage, 12 administrative districts were divided into Type 1 urban districts, Type 2 suburban districts and Type 3 rural districts based on economic levels. From each of these three groups, a district was systematically selected. The first stage included 3 districts. Two communities were randomly chosen from each district for the second stage. Subjects aged 60 years or more with hypertension living in the selected communities were invited to participate for the third stage. The cluster intra-group correlation intraclass correlation coefficient (ICC) is 0.02. Ethics approval was obtained from the Ethics Committee of Zhejiang Hospital, and all participants signed an informed consent.

In the period from October 2010 to April 2011, 11000 subjects with hypertension older than 60 were recruited. In the final analysis, 356 subjects were excluded because of lack of information or low compliance. A total of 10644 subjects were included in the analysis (response rate was 96.7\%); there were no heterogeneities between the excluded 356 patients and the included 10644 patients. The response rates of the 3 different clusters were $96.36 \%, 94.37 \%$ and $98.78 \%$ respectively, there were no significant differences $(P=0.34)$.

\section{Field survey and quality control}

Data collection of this field survey included a questionnaire interview, physical examinations and biochemical examinations. A standardized questionnaire was administered by trained general practitioners in community public health service centers during a face-to-face individual interview. The questionnaire included demographic information such as age, areas of residence, education and health behaviors such as history of smoking, alcohol consumption, diet and physical activity. Physical examinations performed by trained nurses included height, weight, waist circumference, blood pressure (BP) and biochemical examinations including fasting plasma glucose (FPG) and lipid profile.

Weight and height were measured with subjects standing without shoes and wearing light clothing. Participants stood upright with the head in Frankfort plane for height measurement. Height was recorded to the nearest $0.5 \mathrm{~cm}$, and weight was recorded to the nearest $100 \mathrm{~g}$. Body-massindex (BMI) was calculated as weight in kilograms over height in meters squared [weight $\left.(\mathrm{kg}) /(\text { height }(\mathrm{m}))^{2}\right]$ [7] . Waist circumference was measured at the level of the iliac crest using a non-elastic tape measure.

Blood specimens were collected in vacuum tubes after at least 10 hours of overnight fasting, for the measurement of plasma glucose concentration and serum concentrations of total cholesterol and triglycerides. Plasma glucose was measured with the glucose oxidase method. Lipids were measured using Beckman auto analyzer at the biochemistry laboratory of Zhejiang Hospital [7].

Table 1 Distribution of socio demographic factors among participants, by gender $(n=10644)$

\begin{tabular}{|c|c|c|c|}
\hline Variables & $\begin{array}{l}\text { Men } \\
(n=5117)\end{array}$ & $\begin{array}{l}\text { Women } \\
(n=5527)\end{array}$ & P-value \\
\hline Age (years) & $70.4 \pm 7.3$ & $70.3 \pm 7.6$ & 0.008 \\
\hline BMI (kg/m2) & $23.6 \pm 2.9$ & $24.9 \pm 3.4$ & 0.003 \\
\hline \multicolumn{4}{|l|}{ Blood pressure (mm Hg) } \\
\hline Systolic & $142.7 \pm 15.7$ & $142.6 \pm 15.6$ & 0.77 \\
\hline Diastolic & $84.38 \pm 8.96$ & $83.6 \pm 8.8$ & 0.19 \\
\hline \multicolumn{4}{|l|}{ Area of residence, $n(\%)$} \\
\hline Urban & $1468(28.7)$ & $1542(27.9)$ & 0.37 \\
\hline Suburban & $2144(41.9)$ & $2337(42.3)$ & \\
\hline Rural & $1505(29.4)$ & $1648(29.8)$ & \\
\hline \multicolumn{4}{|l|}{ Education, n (\%) } \\
\hline College or higher & $271(5.3)$ & $116(2.1)$ & $<0.001$ \\
\hline Middle & $1039(20.3)$ & $668(12.1)$ & \\
\hline Primary & $2446(47.8)$ & 1766 (31.9) & \\
\hline Illiterate & $1361(26.6)$ & $2977(53.9)$ & \\
\hline $\begin{array}{l}\text { Family history of hypertension, } \\
\mathrm{n}(\%)\end{array}$ & 951 (18.6) & $995(18.0)$ & 0.08 \\
\hline Smoker, n (\%) & $1229(24.0)$ & $425(7.7)$ & $<0.001$ \\
\hline Alcohol intake, n (\%) & $1298(25.4)$ & $452(8.2)$ & $<0.001$ \\
\hline Overweight, n (\%) & $1470(28.7)$ & $1678(30.4)$ & 0.01 \\
\hline Obesity, n (\%) & $315(6.2)$ & $531(9.6)$ & 0.003 \\
\hline \multicolumn{4}{|l|}{ Biochemical measurements } \\
\hline $\mathrm{FBG}(\mathrm{mmol} / \mathrm{L})$ & $5.32 \pm 1.14$ & $5.51 \pm 1.33$ & 0.002 \\
\hline $\mathrm{TG}(\mathrm{mmol} / \mathrm{L})$ & $1.51 \pm 0.93$ & $1.75 \pm 1.08$ & 0.001 \\
\hline $\mathrm{TC}(\mathrm{mmol} / \mathrm{L})$ & $4.48 \pm 1.00$ & $4.60 \pm 1.06$ & 0.03 \\
\hline $\mathrm{HDL}-\mathrm{C}(\mathrm{mmol} / \mathrm{L})$ & $1.45 \pm 0.75$ & $1.40 \pm 0.58$ & 0.06 \\
\hline
\end{tabular}


BP measurements were performed using standardized mercury sphygmomanometers in this study. Subjects were advised to avoid consuming alcohol or tobacco, ingesting tea or coffee, or engaging in exercise for at least 30 minutes before BP measurement.
In addition, subjects were asked to rest for at least 15 minutes before BP testing in a quiet room. The average of two measurements taken 5 minutes apart will be used, but if systolic BP (SBP) measurements differed by $10 \mathrm{mmHg}$ or greater, or diastolic BP (DBP)

Table 2 Control of hypertension among elderly hypertensive patients in Southern China in 2011

\begin{tabular}{|c|c|c|c|c|c|c|}
\hline \multirow[t]{2}{*}{ Variables } & \multirow[t]{2}{*}{ Normal } & \multirow[t]{2}{*}{ Pre-hypertension } & \multicolumn{2}{|c|}{ Hypertension } & \multirow{2}{*}{$\begin{array}{l}\text { Control } \\
\text { rate }(\%)\end{array}$} & \multirow[t]{2}{*}{ P-value } \\
\hline & & & Stage II & Stage III & & \\
\hline All subjects, n (\%) & $138(1.3)$ & $3532(33.2)$ & $2885(27.1)$ & $25(0.2)$ & 44.6 & \\
\hline \multicolumn{7}{|l|}{ Sex } \\
\hline Women & $66(1.2)$ & $1895(34.3)$ & $1470(26.6)$ & $7(0.1)$ & 46.8 & 0.003 \\
\hline Men & $72(1.4)$ & $1637(32.0)$ & $1415(27.6)$ & $18(0.3)$ & 42.6 & \\
\hline \multicolumn{7}{|l|}{ Age, n (\%) } \\
\hline $60-69$ years & $77(1.4)$ & $1817(34.3)$ & $1309(24.7)$ & $11(0.2)$ & 50.8 & $<0.001$ \\
\hline 70-79 years & $45(1.2)$ & $1235(31.5)$ & $1158(29.5)$ & $9(0.2)$ & 40.7 & \\
\hline$\geq 80$ years & $16(1.1)$ & $430(30.2)$ & $478(33.5)$ & $5(0.4)$ & 37.6 & \\
\hline \multicolumn{7}{|l|}{ Area of residence, $n(\%)$} \\
\hline Urban & $105(3.3)$ & $1119(35.5)$ & $663(21.0)$ & $6(0.2)$ & 51.1 & $<0.001$ \\
\hline Suburban & $55(1.2)$ & 979 (21.8) & $1511(33.6)$ & $13(0.3)$ & 31.4 & \\
\hline Rural & $23(0.8)$ & $708(23.5)$ & $898(29.8)$ & $6(0.2)$ & 34.2 & \\
\hline \multicolumn{7}{|l|}{ Education, $\mathrm{n}(\%)$} \\
\hline College or higher & $5(1.3)$ & $131(35.6)$ & $98(26.7)$ & $1(0.2)$ & 49.2 & $<0.001$ \\
\hline Middle & $23(1.4)$ & $557(33.7)$ & $440(26.6)$ & $2(0.1)$ & 45.2 & \\
\hline Primary & $33(0.8)$ & $1191(29.2)$ & $1113(27.3)$ & $9(0.2)$ & 40.2 & \\
\hline Illiterate & $34(0.8)$ & $1038(24.7)$ & $1297(30.8)$ & $13(0.3)$ & 33.7 & \\
\hline Family history of hypertension, $\mathrm{n}(\%)$ & $62(1.2)$ & $2010(39.3)$ & $1006(19.7)$ & $5(0.1)$ & 42.8 & \\
\hline Smoker, n (\%) & $34(1.0)$ & $1016(30.4)$ & $968(28.9)$ & $5(0.1)$ & 38.2 & \\
\hline Drinker, n (\%) & $37(1.1)$ & $1021(30.4)$ & $961(28.6)$ & $5(0.1)$ & 39.4 & \\
\hline Overweight, n (\%) & $28(0.8)$ & $998(30.2)$ & $984(29.8)$ & $4(0.1)$ & 37.4 & \\
\hline Obesity, n (\%) & $31(1.1)$ & $751(26.0)$ & $898(31.1)$ & $7(0.2)$ & 33.3 & \\
\hline \multicolumn{7}{|l|}{ FBG (mmol/L) } \\
\hline Normal & $67(1.0)$ & $2527(36.4)$ & $1856(26.8)$ & $6(0.1)$ & 50.6 & $<0.001$ \\
\hline IFG & $7(1.1)$ & $178(28.2)$ & $194(30.7)$ & $9(1.4)$ & 40.4 & \\
\hline $\mathrm{DM}$ & $2(0.4)$ & 135 (25.9) & $161(30.9)$ & $10(1.9)$ & 36.5 & \\
\hline \multicolumn{7}{|l|}{ TG (mmol/L) } \\
\hline Normal & $50(1.1)$ & 1516 (33.3) & $1159(25.4)$ & $6(0.1)$ & 48.7 & $<0.001$ \\
\hline Slightly high & $14(1.1)$ & $324(25.0)$ & $452(34.9)$ & $9(0.5)$ & 36.4 & \\
\hline High & $6(0.6)$ & $256(23.7)$ & $360(33.4)$ & $10(0.9)$ & 31.4 & \\
\hline \multicolumn{7}{|l|}{$\mathrm{TC}(\mathrm{mmol} / \mathrm{L})$} \\
\hline Normal & $58(1.1)$ & $1542(27.9)$ & 1639 (29.6) & $9(0.2)$ & 45.9 & 0.003 \\
\hline Slightly high & $12(0.9)$ & $371(27.1)$ & $422(30.8)$ & $6(0.4)$ & 42.2 & \\
\hline High & $1(0.3)$ & $114(31.7)$ & $91(25.3)$ & $10(2.8)$ & 37.4 & \\
\hline \multicolumn{7}{|l|}{ HDL-C (mmol/L) } \\
\hline Normal & $86(1.2)$ & 1981 (26.9) & $2174(29.5)$ & $35(0.5)$ & 43.3 & 0.004 \\
\hline Low & $93(1.3)$ & $1782(24.2)$ & $2144(29.1)$ & $14(0.2)$ & 40.8 & \\
\hline
\end{tabular}

${ }^{1} \mathrm{P}$-value: Comparisons among control rates by chi-square test. 
differed by $5 \mathrm{mmHg}$ or greater, a third measurement will be taken. In this instance the average of the two closest SBP and two closest DBP measurements will be used to define the BP [8].

Knowledge about hypertension was tested by questionnaire including the normal blood pressure values, and some healthy lifestyles related to hypertension. Awareness of hypertension was defined as subjects knowing their own blood pressure values. Treatment of hypertension was defined as taking a prescribed medicine for management of hypertension.

\section{Definition}

According to the Chinese Guidelines on Prevention and Control of Hypertension [9], hypertension is defined as $\mathrm{SBP} \geq 140 \mathrm{mmHg}$ and/or $\mathrm{DBP} \geq 90 \mathrm{mmHg}$, or self-reported treatment of hypertension with antihypertensive medication. Pre-hypertension is defined as $120 \mathrm{mmHg} \leq \mathrm{SBP} \leq 139 \mathrm{mmHg}$ and/or $80 \mathrm{mmHg} \leq$ $\mathrm{DBP} \leq 89 \mathrm{mmHg}$, Stage II hypertension is defined as $160 \mathrm{mmHg} \leq \mathrm{SBP} \leq 179$ and/or $100 \mathrm{mmHg} \leq \mathrm{DBP} \leq$ $109 \mathrm{mmHg}$, and stage III hypertension is defined as $\mathrm{SBP} \geq 180 \mathrm{mmHg}$ and/or $\mathrm{DBP} \geq 110 \mathrm{mmHg}$. According to the recent JNC 8 Hypertension Guidelines, a BP goal of less than $150 / 90 \mathrm{mmHg}$ for hypertensive persons aged 60 years or older is defined as control of hypertension [10].

According to the Chinese criteria, overweight is defined as $24 \mathrm{~kg} / \mathrm{m}^{2} \leq$ body mass index $(\mathrm{BMI})<28 \mathrm{~kg} / \mathrm{m}^{2}$; obesity was defined as $B M I \geq 28 \mathrm{~kg} / \mathrm{m}^{2}$ [11]. Fasting plasma glucose (FPG) is classified as impaired fasting glucose (IFG) with $6.1 \mathrm{mmol} / \mathrm{L} \leq \mathrm{FBG} \leq 6.99 \mathrm{mmol} / \mathrm{L}$, and diabetes mellitus (DM) as $\mathrm{FBG} \geq 7.0 \mathrm{mmol} / \mathrm{L}$ [11]. Serum triglycerides (TG) are classified as moderately high TG $(1.7 \mathrm{mmol} / \mathrm{L} \leq \mathrm{TG} \leq 2.25 \mathrm{mmol} / \mathrm{L})$; high $\mathrm{TG}$ (TG $\geq 2.26 \mathrm{mmol} / \mathrm{L}$ ). Serum total cholesterol (TC) is categorized as moderately high TC $(5.18 \mathrm{mmol} / \mathrm{L} \leq \mathrm{TC} \leq$ $6.19 \mathrm{mmol} / \mathrm{L})$; high TC $(\mathrm{TC} \geq 6.22 \mathrm{mmol} / \mathrm{L})$. Low serum high-density lipoprotein cholesterol (HDL-C) are defined as HDL-C $<1.04 \mathrm{mmol} / \mathrm{L}$ [11].

Subjects who smoked one cigarette or more per day for over 6 months were defined as smokers, and alcohol drinkers were assessed by asking subjects whether they had consumed more than once every week in the last 12 months. Subjects who consumed more than 10 grams salt per day for over 6 months were defined as excessive salt users.

\section{Statistical analysis}

The sampling design including stratification, clustering and sampling weights (accounting for differential probabilities of selection and also a post-stratification on gender, age) was taken into account in all estimates and analyses using the specific SAS commands.
Epidata 3.0 was used for data entry and validation and SAS 9.2 for data management and analysis. Sociodemographic characteristics, physical measurements and hypertension status of participants were summarized using frequencies (percentages) or means and standard deviations. Mean values and proportions were compared by the Student's t-test and chi-square test, respectively. The trends in prevalence of hypertension associated factors across categories were analyzed using chi-square test. And the strength of associations of socio-demographic associated factors of hypertension was assessed for binary response variable (uncontrolled hypertension yes/no) by Odds-Ratios (OR) estimated in logistic regression models. Crude associations were first assessed using univariate models, then associations were assessed using multivariate models, and 95\% confidence intervals were calculated. The final model was evaluated by goodness of fit. Significance level was set at $\mathrm{p}<0.05$ for all hypothesis tests.

\section{Results}

\section{Characteristics of the studied population}

The 10644 participants (mean age of 70.33 years) included 5527 women (51.93\%), 5117 men (48.1\%), 3148 overweight subjects (29.57\%), 846 (7.95\%) obese subjects, 1654 smokers (15.54\%) and 1750 drinkers (16.44\%). Men, compared with women, had a lower BMI, FBG, TG, TC and higher level of education; reported significantly higher proportions of current smoking, alcohol use, and had a lower prevalence of overweight and obesity (Table 1). The demographic characteristics of participants in different clusters such as gender, age and education level were showed in the Additional file 1.

\section{Control of hypertension}

Control of hypertension for participants of this survey is presented in Table 2. Of the 10644 hypertensive patients

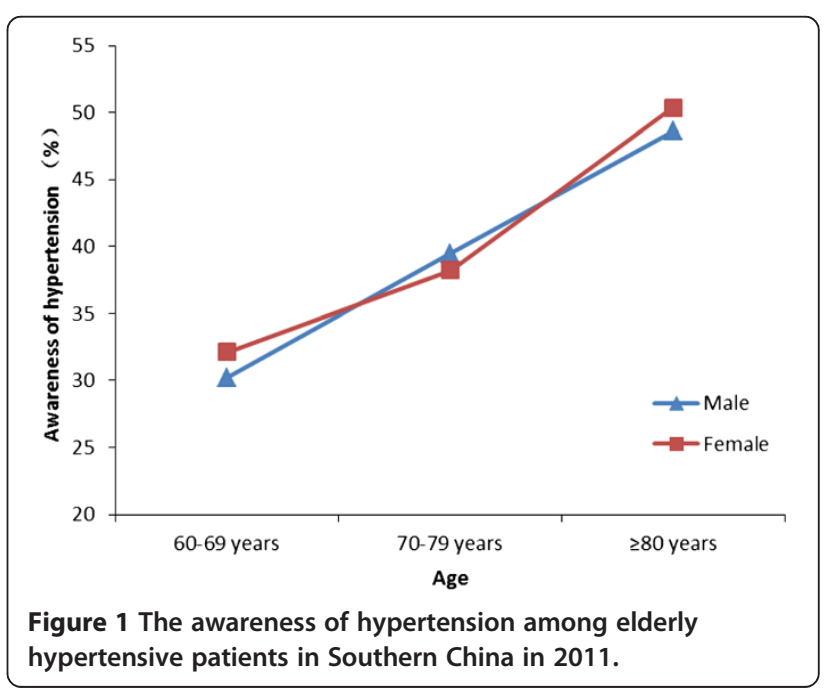




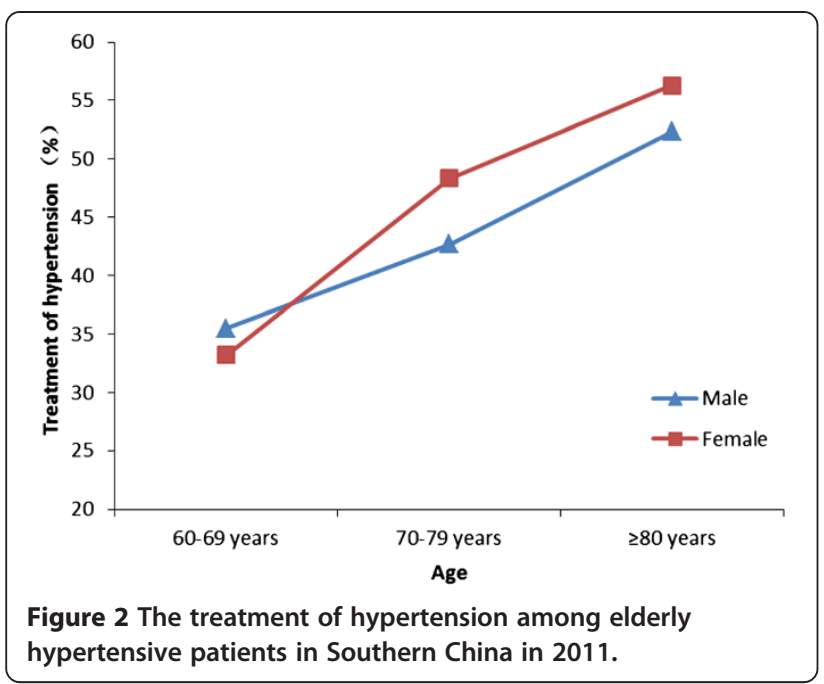

aged 60 years or older, 4747 achieved a BP under 150/ $90 \mathrm{mmHg}$. The control rate of hypertension was $44.6 \%$ according to the JNC 8 Guidelines, the control rate was $34.5 \%$ if the BP goal of less than $140 / 90 \mathrm{mmHg}$ was defined as control of hypertension. And 27.3\% participants had BP of more than $160 / 100 \mathrm{mmHg}$ (stage II and stage III hypertension).

Compared with men, women had slightly higher control rate of hypertension $(46.8 \%$ vs. $42.6 \%, P=0.003)$, and the control rate decreased with older age $(P<0.001)$. Participants living in suburban areas had lower control rates of hypertension compared with living in rural and urban areas $(31.4 \%$ vs. $34.2 \%$ vs. $51.1 \%, \mathrm{P}<0.0001)$. The control rate was higher among those with lower education levels and those with higher BMI's (all $\mathrm{P}<0.001$ ). The rate of uncontrolled hypertension was increased with age and BMI, and decreased with the level of education. Smokers, drinkers, and the groups with family history of hypertension, lower HDL-C, high FBG or TC had lower control rate of hypertension (Table 2).
Prevalence of stage II and stage III hypertension differed by gender. Overall they were higher for men (all $\mathrm{P}<0.001$ ), and the prevalence of stage II and stage III hypertension increased with age; there were statistically significant $(\mathrm{X} 2=47.92, P=0.02)$.

\section{Awareness and treatment of hypertension}

Awareness of hypertension was defined as subjects knowing their own blood pressure values. In the 10644 hypertensive subjects, 4924 (46.27\%) were aware of their normal blood pressure values, 5357 (50.33\%) were taking antihypertensive drugs. Men, compared with women, had slightly lower rates of awareness $(42.05 \%$ vs. $48.69 \%, P=0.003)$ and treatment $(47.51 \%$ vs. $52.06 \%, P<0.001)$. In men as well as women, the awareness and treatment rates of hypertension were higher with older age (all $P<0.001$, Figures 1 and 2).

\section{Antihypertensive medications among treated patients}

Table 3 showed the use of antihypertensive medications according to areas among the 5357 treated hypertensive patients. The results showed that $68.57 \%$ of treated hypertensives used combination therapy, and $32.36 \%$ chose monotherapy. Urban participants, compared with suburban and rural participants, more frequently used a combination of antihypertensive drugs including single pill combination treatment $(P<0.001$, Table 3). The control rate was higher among subjects using combination of antihypertensive medications compared with that of using monotherapy $(62.2 \%$ vs. $52.4 \%, P<0.001)$.

\section{Factors associated with uncontrolled hypertension}

Logistic regression models including crude model and adjusted model were used to assess factors associated with uncontrolled hypertension, respectively. The model adjusted for demographic factors such as gender, age, areas, showed that elderly, living in suburban and rural areas compared with living in urban areas, low level of education, family history of hypertension, smoking,

Table 3 Prevalence of use of commonly prescribed classes of anti-hypertension medications among hypertensive participants $(\mathbf{n}, \%)$

\begin{tabular}{|c|c|c|c|c|c|}
\hline Medication & Urban $(n=3010)$ & Suburban $(n=4481)$ & Rural $(n=3153)$ & All $(n=10644)$ & P-value ${ }^{1}$ \\
\hline Monotherapy & $764(25.4)$ & $1675(37.4)$ & $1006(31.9)$ & $3445(32.4)$ & $<0.001$ \\
\hline DIU & $65(2.2)$ & $443(9.9)$ & $139(4.4)$ & $647(6.1)$ & 0.001 \\
\hline ACEI/ARB & $157(5.2)$ & $313(7.0)$ & $174(5.5)$ & $644(6.1)$ & 0.003 \\
\hline BB & $22(0.7)$ & $57(1.3)$ & $49(1.5)$ & $128(1.2)$ & 0.04 \\
\hline CCB & $520(17.3)$ & $862(19.2)$ & $644(20.4)$ & $2026(19.0)$ & 0.04 \\
\hline Combination & $2246(74.6)$ & 2906 (62.6) & $2147(68.1)$ & 7299 (68.6) & $<0.001$ \\
\hline Fixed-dose combination & $1426(47.4)$ & $1748(39.0)$ & $1578(50.1)$ & $4752(44.6)$ & $<0.001$ \\
\hline Single pill combination & $863(28.7)$ & $946(21.1)$ & $712(20.6)$ & $2521(23.7)$ & 0.002 \\
\hline Free combination & $43(1.4)$ & $212(4.7)$ & $143(4.5)$ & $398(3.7)$ & 0.012 \\
\hline
\end{tabular}

${ }^{1} \mathrm{P}$-value: Comparisons among urban, suburban and rural subjects by chi-square test. 
alcohol use, excessive salt consumption, lack of physical activity, overweight and obesity and high FPG were associated with uncontrolled hypertension (Table 4).

In the adjusted model, the associations between uncontrolled hypertension and smoking, alcohol use, lack of physical activity and higher FPG were more pronounced in men than women. The associations between uncontrolled hypertension and TG and TC were less pronounced for men (Table 4).

\section{Discussion}

Hypertension is a major independent risk factor for cardiovascular disease and stroke. It has been estimated that more than one quarter of the world adult population had hypertension in the year 2000, and that this would increase to $29 \%$ by the year 2025 [7]. Zhejiang province has a rapidly aging population with the percentage of older people increasing each year, which is an important factor associated with hypertension, special attention should be given to the elderly patients.

Our study indicates that the rate of controlled hypertension among patients older than 60 in Southern China (34.5\%) is higher than that in Northern parts of China $(27.5 \%)$ and lower than developed countries such as the United States $(54.9 \%)[12,13]$, probably due to the different living styles and dietary habits [14].

Table 4 Factors associated with uncontrolled hypertension among elderly hypertensive patients in Southern China in 2011 analyzed by crude and adjusted regression model

\begin{tabular}{|c|c|c|c|c|c|c|}
\hline \multirow[t]{2}{*}{ Variables } & \multicolumn{2}{|c|}{ Total $(\mathrm{n}=10644)$} & \multicolumn{2}{|c|}{ Men $(n=5117)$} & \multicolumn{2}{|c|}{ Women $(n=5527)$} \\
\hline & $\operatorname{COR}^{1}(95 \% C l)^{3}$ & $\operatorname{AOR}^{2}(95 \% \mathrm{Cl})^{3}$ & $\operatorname{COR}^{1}(95 \% \mathrm{Cl})^{3}$ & $\operatorname{AOR}^{2}(95 \% C l)^{3}$ & $\operatorname{COR}^{1}(95 \% C l)^{3}$ & $\operatorname{AOR}^{2}(95 \% C I)^{3}$ \\
\hline \multicolumn{7}{|l|}{ Age (ref: 60-69 years) } \\
\hline 70-79 years & 1.5 (1.3-1.9) & $1.6(1.4-2.2)$ & 1.7 (1.3-1.9) & $1.9(1.6-2.7)$ & 1.5 (1.0-1.8) & $1.7(1.2-2.4)$ \\
\hline$\geq 80$ years & $1.8(1.5-2.1)$ & $1.9(1.6-2.6)$ & $1.8(1.5-2.1)$ & $2.2(1.5-3.3)$ & $1.4(1.0-1.6)$ & $1.6(1.2-1.9)$ \\
\hline \multicolumn{7}{|l|}{ Area of residence (ref: Urban) } \\
\hline Suburban & $1.5(1.2-1.6)$ & $1.6(1.1-1.9)$ & $1.4(1.0-1.9)$ & $1.7(1.2-2.5)$ & $1.1(1.1-1.6)$ & $1.4(1.0-2.0)$ \\
\hline Rural & $1.3(1.1-1.6)$ & $1.4(1.1-2.1)$ & $1.3(1.0-2.0)$ & $1.5(1.1-2.2)$ & $1.0(1.0-1.8)$ & $1.3(1.0-1.8)$ \\
\hline \multicolumn{7}{|l|}{ Education (ref: College or higher) } \\
\hline Middle & $1.7(1.4-2.3)$ & $1.3(0.8-2.0)$ & $1.6(1.3-2.3)$ & $1.2(0.7-1.8)$ & $1.7(1.3-2.5)$ & $1.3(0.9-1.9)$ \\
\hline Primary & $2.0(1.5-2.7)$ & 1.5 (1.2-1.9) & $2.0(1.7-2.6)$ & $1.9(1.5-2.6)$ & $1.9(1.5-2.9)$ & $1.4(0.9-2.1)$ \\
\hline Illiterate & $2.3(1.7-2.8)$ & $2.1(1.6-2.7)$ & $2.4(1.8-3.0)$ & $2.9(2.1-4.1)$ & $2.2(1.6-2.8)$ & $1.7(1.3-2.3)$ \\
\hline Family history of hypertension (ref: No) & $1.8(1.5-2.6)$ & $1.2(1.0-1.3)$ & $1.5(1.0-2.0)$ & $1.6(1.1-2.4)$ & $1.9(1.1-2.2)$ & $2.0(1.2-2.6)$ \\
\hline Smoker (ref: Nonsmoker) & $2.7(2.1-4.1)$ & $2.8(1.6-3.9)$ & $3.4(1.2-2.2)$ & $3.8(2.1-4.5)$ & $2.3(1.2-3.8)$ & $2.5(1.4-3.8)$ \\
\hline Drinker (ref: Nondrinker) & $2.5(1.5-3.9)$ & $2.0(0.9-3.1)$ & $2.7(1.6-4.1)$ & $2.1(1.2-3.3)$ & $2.2(1.2-3.3)$ & $1.9(0.8-2.6)$ \\
\hline Excessive salt (ref: No) & $1.3(1.0-1.6)$ & $1.5(1.1-2.4)$ & $1.0(0.9-1.2)$ & $1.2(0.9-2.1)$ & $0.9(0.5-1.1)$ & $0.6(0.2-1.1)$ \\
\hline Physical activity < 2 hours/week (ref: No) & $0.6(0.1-0.9)$ & $0.8(0.0-0.9)$ & $0.7(0.0-0.9)$ & $0.8(0.5-0.9)$ & $0.6(0.1-1.1)$ & $0.7(0.2-1.2)$ \\
\hline \multicolumn{7}{|l|}{ BMI (ref: Normal) } \\
\hline Overweight & $2.5(2.0-3.6)$ & $2.3(1.5-4.0)$ & $2.1(1.8-2.5)$ & $2.4(1.2-3.2)$ & $2.4(2.1-2.8)$ & $2.5(1.5-3.5)$ \\
\hline Obesity & $2.9(1.9-3.8)$ & $3.3(2.9-4.3)$ & $2.4(1.9-3.0)$ & $3.0(1.3-3.9)$ & $2.5(2.1-3.1)$ & $2.6(1.4-3.8)$ \\
\hline \multicolumn{7}{|l|}{ FPG (ref: Normal) } \\
\hline IFG & $2.4(1.5-3.2)$ & $2.5(1.2-3.2)$ & $2.5(1.5-3.2)$ & $2.6(1.9-3.6)$ & $2.4(1.6-3.3)$ & $3.2(0.8-4.0)$ \\
\hline $\mathrm{DM}$ & $2.7(1.4-4.2)$ & $1.2(1.0-2.4)$ & $3.1(2.3-4.0)$ & $3.3(2.3-4.2)$ & $2.8(1.9-4.3)$ & $2.5(1.2-3.2)$ \\
\hline \multicolumn{7}{|l|}{ TG (ref: Normal) } \\
\hline Slightly high & $2.6(1.3-2.9)$ & $2.1(0.8-3.2)$ & $2.2(1.3-3.1)$ & $2.3(0.9-3.1)$ & $2.5(1.5-2.9)$ & $2.6(1.9-3.5)$ \\
\hline High & $2.8(1.4-3.2)$ & $2.5(0.9-2.9)$ & $2.5(1.2-3.3)$ & $2.6(1.6-3.5)$ & $2.7(1.5-3.2)$ & $2.8(2.0-3.6)$ \\
\hline \multicolumn{7}{|l|}{ TC (ref: Normal) } \\
\hline Slightly high & $0.6(0.3-1.1)$ & $0.5(0.0-1.3)$ & $0.5(0.1-0.8)$ & $0.6(0.2-0.9)$ & $0.6(0.0-1.6)$ & $1.1(1.0-1.3)$ \\
\hline High & $0.7(0.4-0.9)$ & $0.2(0.0-1.6)$ & $0.9(0.6-1.2)$ & $1.0(0.6-1.5)$ & $0.8(0.2-0.9)$ & $0.7(0.0-0.9)$ \\
\hline Low HDL-C (ref: Normal) & $0.6(0.4-0.9)$ & $0.7(0.1-1.1)$ & $1.3(1.0-1.8)$ & $1.1(0.8-2.1)$ & $1.2(1.0-1.9)$ & $1.2(1.0-1.8)$ \\
\hline
\end{tabular}

${ }^{1}$ COR: Crude odds ratio in the model with unadjusted association.

${ }^{2} \mathrm{AOR}$ : Adjusted odds ratios in the model with multivariate models adjusted by age group and area of residence.

${ }^{3} 95 \% \mathrm{Cl}, 95 \%$ confidence interval. 
Although hypertension awareness, treatment and control among elderly patients have markedly improved compared with the elderly subgroup ( $\geq 60$ years of age) of the 2002 NNHS [15], they were higher than the study surveyed in Beijing [16] and some developed countries [17-19], the control of hypertension was still unsatisfactory among hypertensive patients.

Most patients in our study used combination therapy of antihypertensive medications, those using longacting antihypertensive medications had more higher control rate; and those using a monotherapy of shortacting antihypertensive medications had lower control rate. There were more patients using inappropriate antihypertensive medications in suburban and rural areas, possibly due to the lack of qualified physicians in these areas.

Old age, high FBG, overweight, obesity and family history of hypertension are traditional associated factors of hypertension [20-22]. Some reports have shown that excessive alcohol use and tobacco consumption are also important causes of hypertension [23-25]; results in this study provide additional support to these hypotheses. Adjusted odds ratios (AOR) were greater in the groups with higher age and lower education, which is similar with some other studies [26-28]. These results also showed that excessive use of salt and lack of physical activity were associated with higher rates of uncontrolled hypertension. These further confirmed some of the previous reports [29-32], but were in contrast with the Awoke study [33].

Compared with living in urban areas, living in suburban and rural areas are associated factors of uncontrolled hypertension. China is in a rapid urbanization period and in the past few decades, a large number of rural people, such as our study subjects, immigrated to cities or were locally urbanized. They often travel to cities for work and come back home during weekends, and typically have more stress related issues and unhealthy lifestyles that result in uncontrolled hypertension. More effective primary prevention measures should be made in these areas to address the rise in hypertension.

Some limitations needed to be mentioned in this study. Firstly, our study was a cross-sectional survey, which made it difficult to establish a cause-and-effect relationship between associated factors and uncontrolled hypertension. Second, we did not include the socioeconomic status, such as personal or family income, which may be associated with the prevalence of hypertension and lack of adequate control rate. Despite these limitations, the strengths of this study included providing regional representative data and evidence-based references for the control and management of hypertension at a population level.

\section{Conclusions}

Uncontrolled hypertension is highly prevalent in elderly hypertensive patients in Southern China. Although the rates of control, treatment and awareness have increased significantly since 2002, many of the hypertensive patients are unaware of their condition, and the rate of control and treatment remain relatively low, most likely due to the inappropriate use of antihypertensive medications and unhealthy lifestyles. Innovative strategies and efforts to improve the management of hypertension are needed, including the appropriate use of antihypertensive drugs and the intervention of factors associated with hypertension, such as smoking, drinking alcohol, excessive salt consumption, obesity, etc. More populationbased strategies to control and prevent hypertension, including conducting community-based intervention programs, carrying out primary prevention policies and public health services are needed to address this serious problem.

\section{Additional file}

Additional file 1: Distribution of socio demographic factors among participants, by clusters $(n=10644)$.

\section{Abbreviations}

CVD: Cardiovascular disease; BP: Blood pressure; SBP: Systolic blood pressure; DBP: Diastolic blood pressure; BMI: Body mass index; FPG: Fasting blood glucose; TC: Serum total cholesterol; TG: Triglyceride; HDL-C: Serum high density lipoprotein cholesterol; COR: Crude odds ratio; AOR: Adjusted odds ratios; Cl: Confidence intervals; DIU: Diuretics; ACEl: Angiotensin-converting enzyme inhibitors; ARB: Angiotensin receptor blockers; BB: $\beta$-blockers; CCB: Calcium channel blockers.

\section{Competing interests}

The authors declare that they have no competing interests.

\section{Authors' contributions}

XX conceived the protocol and contributed to the study design; LY managed data collection, drafted and finalized writing the manuscript; XT researched literature, contributed to interpretation of the results; HW conducted statistical analyses; JY and WY contributed to the conception and design the study; CLP improved the style of written English. All authors contributed to the final manuscript and have approved its publication.

\section{Acknowledgments}

This study was funded by the Science and Technology Applicability Programs for Public Welfare in Zhejiang province (2011C23001). We thank the assistance given by the staff of Dongpu, Shiqiao, Yuxin, Chaohui, Honghe and Mashan Community Public Health Service Centers in Zhejiang province.

\section{Author details}

'Zhejiang provincial center for cardio-cerebrovascular diseases control and prevention, Zhejiang hospital, 12 Lingyin Road, Hangzhou, Zhejiang 310013, China. ${ }^{2}$ Zhejiang provincial center for disease control and prevention, Hangzhou 310051, China. ${ }^{3}$ Sino-US Diabetes Center, Zhejiang Hospital, 12 Lingyin Road, Hangzhou, Zhejiang 310013, China.

Received: 12 February 2014 Accepted: 21 August 2014 Published: 2 September 2014 


\section{References}

1. Wu Y, Huxley R, Li L, Anna V, Xie G, Yao C, Woodward M, Li X, Chalmers J, Gao R, Kong L, Yang X, China NNHS Steering Committee; China NNHS Working Group: Prevalence, awareness, treatment, and control of hypertension in china: data from the China National Nutrition and Health Survey 2002. Circulation 2008, 118:2679-2686.

2. Whitworth JA: World Health Organization (WHO)/International Society of Hypertension (ISH) statement on management of hypertension. J Hypertens 2003, 2003(21):1983-1992.

3. Danaei G, Finucane MM, Lin JK, Singh GM, Paciorek CJ, Cowan MJ, Farzadfar F, Stevens GA, Lim SS, Riley LM, Ezzati M, Global Burden of Metabolic Risk Factors of Chronic Diseases Collaborating Group (Blood Pressure): National, regional, and global trends in systolic blood pressure since 1980: systematic analysis of health examination surveys and epidemiological studies with 786 country-years and 5.4 million participants. Lancet 2011, 377:568-577.

4. Wang J, Ning X, Yang L, Lu H, Tu J, Jin W, Zhang W, Su TC: Trends of hypertension prevalence, awareness, treatment and control in rural areas of northern China during 1991-2011. J Hum Hypertens 2014, 28(1):25-31.

5. Li LM, Rao KQ, Kong LZ, Yao CH, Xiang HD, Zhai FY, Ma GS, Yang XG: Technical Working Group of China National Nutrition and Health Survey. A description on the Chinese national nutrition and health survey in 2002. Chin J Epidemiol 2005, 26:478-484.

6. $X u B, X u Z, X u X, C a i, Q, X u Y$ : Prevalence, awareness, treatment, and control of hypertension among residents in Guangdong Province, China, 2004 to 2007. Circ Cardiovasc Qual Outcomes 2013, 6:217-222.

7. Wang H, Zhang X, Zhang J, He Q, Hu R, Wang L, Su D, Xiao Y, Pan J, Ye Z: Factors associated with prevalence, awareness, treatment and control of hypertension among adults in Southern China: a community-based, Cross-Sectional Survey. PLOS ONE 2013, 8(5):e62469.

8. Chalmers J, MacMahon S, Mancia G, Whitworth J, Beilin L, Hansson L, Neal B, Rodgers A, Ni Mhurchu C, Clark T: World Health Organization-International Society of Hypertension Guidelines for the management of hypertension. Guidelines subcommittee of the World Health Organization. Clin Exp Hypertens 1999, 21:1009-1060

9. Committee for Revision of Chinese Guidelines for Prevention and Treatment of Patients with Hypertension: Chinese guidelines for prevention and treatment of patients with hypertension. Chin J Hypertens 2005, 134:2-41.

10. James PA, Oparil S, Carter BL, Cushman WC, Dennison-Himmelfarb C, Handler J, Lackland DT, LeFevre ML, MacKenzie TD, Ogedegbe O, Smith SC Jr, Svetkey LP, Taler SJ, Townsend RR, Wright JT Jr, Narva AS, Ortiz E: 2014 evidence-based guideline for the management of high blood pressure in adults report from the panel members appointed to the Eighth Joint National Committee (JNC 8). JAMA 2013, 18:1-14

11. Joint Committee for Developing Chinese guidelines on Prevention and Treatment of Dyslipidemia in Adults: Chinese guidelines on prevention and treatment of dyslipidemia in adults. Chin J Cardio/ 2007, 5:390-419.

12. Meng XJ, Dong GH, Wang D, Liu MM, Lin Q, Tian S, Xu LX, Hou H, Ren YF, Lee YL: Prevalence, awareness, treatment, control, and risk factors associated with hypertension in urban adults from 33 communities of China: the CHPSNE study. J Hypertens 2011, 29:1303-1310

13. Guo F, He D, Zhang W, Walton RG: Trends in prevalence, awareness, management, and control of hypertension among United States Adults, 1999 to 2011. J Am Coll Cardiol 2012, 60:599-606.

14. Reklaitiene R, Tamosiunas A, Virviciute D, Baceviciene M, Luksiene D: Trends in prevalence, awareness, treatment, and control of hypertension, and the risk of mortality among middle-aged Lithuanian urban population in 1983-2009. BMC Cardiovasc Disord 2012, 12:68-72.

15. Sheng CS, Liu M, Kang YY, Wei FF, Zhang L, Li GL, Dong Q, Huang QF, Li Y, Wang JG: Prevalence, awareness, treatment and control of hypertension in elderly Chinese. Hypertens Res 2013, 36:824-828.

16. Cai L, Liu A, Zhang L, Li S, Wang P: Prevalence, awareness, treatment, and control of hypertension among adults in Beijing, China. Clin Exp Hypertens 2012, 34:45-52.

17. Guessous I, Bochud M, Theler JM, Gaspoz JM, Pechere-Bertschi A: 19992009 trends in prevalence, unawareness, treatment and control of hypertension in Geneva, Switzerland. PLoS One 2012, 7:e39877.

18. Khdour MR, Hallak HO, Shaeen M, Jarab AS, Al-Shahed QN: Prevalence, awareness, treatment and control of hypertension in the Palestinian population. J Hum Hypertens 2013, 27(10):623-628.
19. Labeit AM, Klotsche J, Pieper L, Pittrow D, Einsle F, Stalla GK, Lehnert H, Silber S, Zeiher AM, März W, Wehling M, Wittchen HU: Changes in the prevalence, treatment and control of hypertension in Germany? a clinical-epidemiological study of 50.000 primary care patients. PLoS One 2007, 12:e52229

20. Yip W, Wong TY, Jonas JB, Zheng Y, Lamoureux EL, Nangia V, Sabanayagam C Prevalence, awareness, and control of hypertension among Asian Indians living in urban Singapore and rural India. J Hypertens 2013, 31:000-010.

21. Bharucha NE, Kuruvilla T: Hypertension in the Parsi community of Bombay: a study on prevalence, awareness and compliance to treatment. BMC Public Health 2003, 3:1.

22. Hazarika NC, Biswas D, Mahanta J: Hypertension in the elderly population of Assam. J Assoc Physicians India 2003, 51:567-573.

23. Grucza RA, Krueger RF, Racette SB, Norberg KE, Hipp PR, Bierut L: The emerging link between alcoholism risk and obesity in the United States. Arch Gen Psychiatry 2010, 67:1301-1308.

24. Bowman TS, Gaziano JM, Buring JE, Sesso HD: A prospective study of cigarette smoking and risk of incident hypertension in women. J Am Coll Cardiol 2007, 50:2085-2092.

25. Groppelli A, Giorgi DM, Omboni S, Parati G, Mancia G: Persistent blood pressure increase induced by heavy smoking. J Hypertens 1992, 10:495-499.

26. Erem C, Hacihasanoglu A, Kocak M, Deger O, Topbas M: Prevalence of prehypertension and hypertension and associated risk factors among Turkish adults: Trabzon Hypertension Study. J Public Health 2009, 31:47-58.

27. Choi KM, Park HS, Han JH, Lee JS, Lee J, Ryu OH, Lee KW, Cho KH, Yoon D, Baik SH, Choi DS, Kim SM: Prevalence of prehypertension and hypertension in a Korean population: Korean National Health and Nutrition Survey 2001. J Hypertens 2006, 24:1515-1521.

28. Prince MJ, Ebrahim $S$, Acosta D, Ferri CP, Guerra M, Huang Y, Jacob KS, Jimenez-Velazquez IZ, Rodriguez JL, Salas A, Sosa AL, Williams JD, GonzalezViruet M, Jotheeswaran AT, Liu Z: Hypertension prevalence, awareness, treatment and control among older people in Latin America, India and China: a 10/66 cross-sectional population-based survey. J Hypertens 2012, 30:177-187.

29. Malekzadeh MM, Etemadi A, Kamangar F, Khademi H, Golozar A, Islami F, Pourshams A, Poustchi H, Navabakhsh B, Naemi M, Pharoah PD, Abnet CC, Brennan P, Boffetta P, Dawsey SM, Esteghamati A, Malekzadeh R: Prevalence, awareness and risk factors of hypertension in a large cohort of Iranian adult population. J Hypertens 2013, 31:31-36.

30. Steptoe A, McMunn A: Health behaviour patterns in relation to hypertension: the English Longitudinal Study of Ageing. J Hypertens 2009, 27:224-230.

31. Karppanen $\mathrm{H}$, Mervaala E: Sodium intake and hypertension. Prog Cardiovasc Dis 2006, 49(2):59-75.

32. Heikki Karppanen and Eero Mervaala: Sodium intake and hypertension. Progress in 556. Dis 2006, 49(2):59-75.

33. Awoke A, Awoke T, Alemu S, Megabiaw B: Prevalence and associated factors of hypertension among adults in Gondar, Northwest Ethiopia: a community based cross-sectional study. BMC Cardiovasc Disord 2012, 12:113-115.

\section{doi:10.1186/1471-2458-14-903}

Cite this article as: Yang et al: Analysis on associated factors of uncontrolled hypertension among elderly hypertensive patients in Southern China: a community-based, cross-sectional survey. BMC Public Health 2014 14:903. 